\title{
Elementos románicos repintados. Planteamiento de una cuestión incómoda
}

\author{
José Ángel Esteras Martínez y Josemi Lorenzo Arribas \\ Proyecto Cultural Soria Románica*, Fundación Duques de Soria
}

Resumen: Se trata un tema polémico, negligido por la bibliografía: ¿qué hacer en las restauraciones arquitectónicas de edificios románicos cuando sus elementos escultóricos (capiteles, columnas, canecillos...) están repintados según el gusto popular de los dos últimos siglos con colores chillones? Es una cuestión de canon estético y de gusto, ambos mudables según las épocas y el cambio de los criterios. Mientras, se va perdiendo un patrimonio que, además de testimonio histórico, también es artístico, y que entronca, de alguna manera, con el gusto románico de cubrir la arquitectura y sus elementos monumentales de colores vivos y contrastantes, sospechosamente en la misma línea de los repintes que hoy tienden a eliminarse sin demasiada reflexión previa.

Palabras Clave: Románico, arte popular, restauración, canon estético, repintes, Soria

Abstract: This article deals with a controversial subject forgotten by scholars: What must we do with the architectural restorations of Romanesque buildings when their sculptural elements (capitals, columns, corbels...) have been repainted with strident colours according to popular taste of the last two centuries? It is a matter of aesthetic canon and a matter of taste, both of them changeable with the course of time and the changes of criteria. Meanwhile, we are losing a patrimonial legacy that as well as being a historical testimony, it is also artistic, and, that, somehow, is related to the Romanesque taste for covering both architecture and its monumental elements with striking and flashy colours, suspiciously with the same style of repainted elements that we tend to eliminate without a serious and previous reflection nowadays.

Key Words: Romanesque, folk art, restoration, aesthetic canon, repainting elements, Soria (Spain)

Resumo: Trata-se de um tema polémico, abandonado pela bibliografia: que fazer nas restaurações arquitectónicas dos edifícios românicos quando os seus elementos escultóricos (capiteis, colunas, cachorradas...) estão repintados segundo o gosto popular dos dois últimos séculos com cores berrantes? É uma questão de cânone estético e de gosto, ambos variáveis segundo as épocas e a mudança dos critérios. Enquanto que se vai perdendo um património que, para além de ser um testemunho histórico, assim como artístico, e que se cruza de alguma maneira com o gosto românico de cobrir a arquitetura e os seus elementos monumentais de cores vivas e contrastantes que sospechosamente casualmente, figuram na mesma linha dos retoques que hoje tendem a eliminar-se sem demasiada reflexão prévia.

Palavras-chave: Românico, arte popular, restauração, canone estético, retoques, Soria.

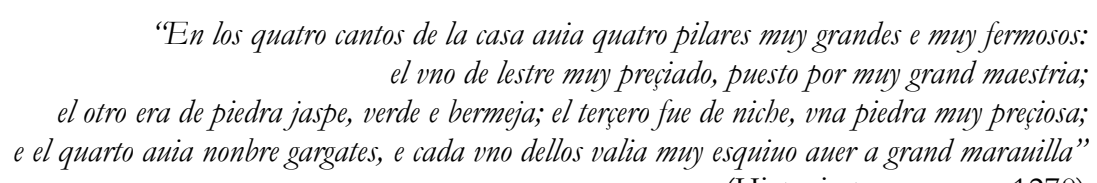

(Historia troyana, ca. 1270)

No pretendemos tratar aquí de manifestaciones pictóricas románicas, sino de elementos románicos singulares (capiteles, columnas y canecillos, fundamentalmente) repintados en época reciente conforme a un gusto popular ajeno a la normatividad académica. Estas páginas no pretenden ser una reflexión teórica sobre la conveniencia o no de las denominaciones al uso al tratar del Románico propio de las pequeñas poblaciones rurales (Románico rural, románico popular...), sino una llamada de atención sobre ejemplos muy concretos que han sido generalmente despreciados 
por restauradores, historiadores del Arte y etnógrafos en torno a unas muestras de gusto popular con pretensiones estéticas o, directamente, artísticas. Este gusto popular ha debido permanecer latente durante muchos años. Luego, se producen surgencias en que aparece, principalmente cuando no hay demasiado control oficial. Haciendo una metáfora ad hoc, el gusto popular, como las pinturas románicas, se encala, o se enluce, para luego volver a salir por sus fueros y reivindicarse ${ }^{1}$. Los pequeños templos rurales son los que recogen más testimonios de esta naturaleza, ya que escapan al gusto oficialista y acumulan intervenciones debidas al ingenio de "artistas" locales que, en ocasiones, no siguen más criterio que el gusto personal.

Aunque forman parte de esta reflexión, no nos vamos a centrar aquí en la decoración mural con que en el Barroco se cubrieron muchos paramentos románicos: una decoración conceptualmente diferente a los ejemplos del pasado siglo XX, en los que el presente análisis se centra. La pretensión decorativa barroca no era únicamente la de embellecer sin más el interior de los templos, sino que, además, trataba de fingir hacia el espectador una ilusión espacial o material. Aquello de lo que carecía la arquitectura preexistente o los materiales que la constituían, que la falta de medios económicos hacía inviable, o que representaba una idealización irrealizable, se suplía con la inclusión del color y la formalización pictórica, añadida al acabado superficial de la, por otro lado, honesta arquitectura románica. Trampantojos, cortinajes, jaspeados o efectos similares que cubrieron paramentos y otros elementos constructivos y escultóricos monumentales (columnas, líneas de imposta...), que bien merecen por sí solos un análisis específico en el ámbito del Románico repintado que en líneas generales aquí se trata de esbozar.

El Románico repintado en el que nos centramos carece de mayores pretensiones que las de dotar de colorido los acabados interiores de los templos, no busca efectos de perspectiva, y cuenta con escasos medios materiales, sin una autoría y sin reconocimiento artístico. Es una manifestación espontánea reflejo de la cultura popular, ajena a tendencias, modas y a los estilos artísticos dominantes en los "círculos culturales" del momento. En definitiva, un reflejo en la contemporaneidad, de la vivencia del Románico en aquellos momentos en los que se materializó su arquitectura, que suele tener su manifestación principal sobre los elementos decorativos más característicos de este arte, lo que supone en ocasiones una contrariedad a los prístinos ojos actuales en los que se revaloriza un Románico filtrado por la estética decimonónica. Directamente, tratan estas páginas sobre los repintados "groseros", pinturas plásticas incluidas, con los que se han "decorado" capiteles y canecillos de no pocas iglesias y ermitas, y que producen un efecto casi inmediato, demoledor, en quienes estamos ahormados a un gusto modelado con criterios académicos. Se excluyen los elementos simplemente encalados, o aquellos a los que se ha aplicado una lechada que también cubre los paramentos interiores del templo, indiferenciándolos cromáticamente, por tanto. El color es el protagonista de estas páginas y de las reflexiones a que dan lugar. El ámbito espacial que se trata es la actual provincia de Soria, lugar muy rico en manifestaciones románicas, territorio donde trabajamos, y que cuenta con buenos ejemplos del objeto que versan estas páginas.

\section{El color, un antiguo compañero de los muros}

Como análisis de partida sobre la utilización del color en la arquitectura a lo largo de la historia, diferenciamos la inclusión de una decoración cromática como aspecto inherente al diseño inicial de un espacio, de la decoración o embellecimiento a posteriori de un elemento arquitectónico preexistente. El diseño cromático formaría parte de la composición y de la unidad estética de los correspondientes elementos arquitectónicos u ornamentales de manera destacada en las decoraciones clásicas, griegas y romanas, y también en obras de etapas posteriores, como ese románico que quizás no se planteaba la posibilidad de iconografiarse, aunque sí pintarse, y del que aún se conservan algunos ejemplos. En éstos, el color, lejos de utilizarse simplemente de un modo aleatorio o suntuoso, se aplicaría siguiendo patrones estudiados que contribuyeran con sus combinaciones a completar la distribución espacial, a reforzar el carácter de la arquitectura y de sus elementos, y a enfatizar en definitiva su belleza como conjunto arquitectónico unitario. El color 
respondería a una función y a una intención en un canon establecido. La obra no se concebiría desde su inicio sin esta culminación cromática, fuera ésta de mayor o menor calado.

Las esculturas griegas y romanas clásicas, las arquitecturas de estos periodos, y la propia arquitectura posterior, prerrománica y románica, han visto cómo la historia les ha privado, de manera natural o forzada, de ese tratamiento cromático original, primordial en muchos casos en sus procesos compositivos. Y de tal modo ha sido así, que a partir del Romanticismo se ha producido una involución estética en Occidente que ha derivado en la valoración de la piedra desnuda como el culmen de la belleza y paradigma de "lo antiguo". En este sentido, quizá el gusto popular por los colores planos, fuertes y resaltantes con que se decoran elementos escultóricos románicos en el siglo XX sea una constante estética que sólo surge en la historia cuando tiene ocasión, y ésta se presenta de manera óptima en los ambientes rurales, ajenos a la normatividad, cuyo aislamiento, o al menos alejamiento de los centros jerárquicos de decisión, facilita que se manifiesten al haber menos control. Estas surgencias periódicas del gusto por el color tratado con rudeza se podrían interpretar, por tanto, como un relicto de una estética de tiempos pasados, asociada entonces a las clases pudientes, que se lo podía costear, que ha devenido en popular con el abaratamiento y el acceso universal a los teñidos y las técnicas de impresión.

Afortunadamente ajenos a esa tendencia, quizás por su propia marginalidad geográfica, los ejemplos que se tratan en el presente artículo parecen corresponder a una continuidad hasta nuestros días de aquellas composiciones iniciales, perdidas u ocultas por el paso de los siglos y del saneamiento periódico de los templos con el enjalbegado de sus muros. Este embellecimiento de elementos preexistentes respondería a este único deseo, lejos de mayores pretensiones compositivas o de contemplar el uso de determinados colores con funciones compositivas específicas o significados carentes de valor en épocas recientes.

Hoy se sabe que los templos prerrománicos y románicos no se dejaban desnudos, con la piedra o la mampostería a la vista. Es más, si había posibilidad, sobre el revoco que los cubría se aplicaban brillantes colores. Significativamente, Isidoro de Sevilla en las Etimologias, afirma en un epígrafe dedicado al embellecimiento de los interiores edilicios: "Embellecimiento es todo lo que se incorpora al edificio para su ornato y decoración, como son los artesonados recamados en oro, las incrustaciones de mármol precioso o las pinturas de diferentes colores" (XIX.11: 448-9), unos colores a los que dedica largos comentarios explicando cómo se obtienen (17: 452-457). La conclusión la aporta un poco más abajo, tratando ya de los colores de los vestidos: "La tintura se llama así porque tiñe; y una tela teñida adquiere otro colorido que la hace más hermosa" (28.1: 476-7). La legislación suntuaria castellana bajomedieval, regulando entre otros extremos el uso de colores en función del rango social, muestra que el imaginario cromático (al margen de su simbología) rigió durante toda la Edad Media. Lo mismo que pensaba Isidoro de los paños lo había de trasladar a los muros. Algo tan costoso y tan maravilloso como la policromía honraba la materia o superficie sobre la que se asentaba, por lo general bastante humilde. Cuanto más costosa fuera la obtención de un color, más valor le aportaba. Cuanta más gama se empleara, más honor, y volvemos a tener en mente los Beatos, testimonios pictóricos conservados más cercanos al sabio de Cartagena que establecen bisagra y continuidad con la estética románica puesto que algunos de ellos se realizan ya en esta época ${ }^{3}$. Para construcciones monocromas, al igual que para paños crudos, ya estaban los lugares que habitaba la gente común, revocados con el color del árido local, muros que acogían la cotidianidad de esa misma gente que vestía con una indumentaria humilde y sin teñir. Cuando los sentidos se hiperestimulaban al entrar al templo (música, incienso...) y las personas pudientes competían por mostrar su poderío, entre otras cosas, policromando sus interiores ¿se iba a escatimar con los colores en los elementos decorativos de la casa de Dios?

El pasaje siguiente es interesante a la hora de comprender lo que se entendía por interior embellecido en los siglos plenomedievales. El Libro de los buenos proverbios que dijeron los filósofos y sabios antiguos, redactado a mediados del siglo XIII, pone el siguiente parlamento en boca de Johanniçio, explicando el gusto de los antiguos (es decir, el gusto contemporáneo al redactor, en este caso coincidente con lo que sabemos que era el gusto premedieval) a la hora de adornar los edificios importantes: 
"Estas yuntas que fazen los philosofos eran porque los rresyes de los griegos y de los otros gentiles amostravan a sus fijos la sapiençia y la philosophía y todas las artes, y enseñávanles todo buen enseñamiento; y fazíanles palaçios con oro y con plata muy pintados de muchas maneras de figuras por tal que oviessen sabor de yr a estos palacios, ca estas eran sus escuelas y por esto avíen mayor sabor de yr allá los moços que aprendíen. Y por esta razón fazíen los judíos muchos entalles en sus sinogas y los christianos en sus yglesias y otrosí los moros pintan sus mezquitas. Tod esto fazen por tal que ayan sabor los omnes de ir allá" (cap. LV).

En esta cita se advierten dos apuntes fundamentales para entender el efecto que tenía la policromía mural sobre la gente que la admiraba. Por un lado, se erigía en recurso "pobre" para reproducir, de alguna manera, el lujo de quienes sí podían costearse los revestimientos interiores a los que Johanniçio se refiere. Si no se podían pagar "figuras", oro y plata, la humilde pintura y la pericia del pintor recreaba tales ambientes. Aun siendo recurso modesto, era mucho más digno y bello que dejar los paramentos sin pintar. Por otro lado, la policromía actuaba como reclamo para atraer a más fieles a los templos. Es un aspecto recurrente que se repite en la historia de la Iglesia: la pugna entre quienes consideraban favorables los efectos escénicos en el adorno y en la liturgia, y quienes los consideraban frívolos y errados 4 .

En las sinagogas, mezquitas e iglesias, por tanto, además de los muros se pintaba y se repintaba todo, tallas, retablos, mobiliario... No se dejaba nada sin colorear, si se podía. En Soria, las pinturas murales románicas de San Baudelio (Casillas de Berlanga), de la ermita de San Miguel (Gormaz), o de la cercana iglesia de la Vera Cruz de Maderuelo (Segovia) son buenos ejemplos de cómo entendían los interiores las gentes que levantaron y habitaron el Románico. En el Barroco, cortinajes y trampantojos volvieron a llenar sistemáticamente de un estallido cromático los muros de los templos, y ya en tiempos más recientes, sin escuelas ni mediaciones culturalistas de por medio, el gusto popular en ocasiones resucitó los colores chillones y las policromías agresivas, siglos después de que en el arte oficial hubieran dejado de emplearse por cuestión de gusto estético.

En la arquitectura románica, los primeros tratamientos cromáticos que acompañan al propio revestimiento de sus muros con capas de encalado, no están exentos de intencionalidad compositiva, buscando otorgar a la arquitectura un cromatismo y una espacialidad uniformes, enfatizando aquellos elementos de la propia construcción y del primigenio repertorio iconográfico. En segunda instancia, la pintura figurativa sobre estos lienzos blancos se presenta como un tratamiento embellecedor que se adapta a un soporte preexistente, y que a su vez persigue diversos fines, entre ellos el escenográfico, que complemente a la propia arquitectura.

\section{El color, símbolo de prestigio}

En la Edad Media, el empleo de determinados pigmentos, extraídos de sustancias de difícil obtención, otorgaba un valor añadido a la obra que se coloreaba así. En este sentido, el color, por sí mismo, se convertía en un símbolo de prestigio, al margen del soporte en que se fijase, sirviendo como ejemplo sublime la iluminación de los Beatos altomedievales y románicos, donde toda la superficie iconografiada se cubría de vivos y resaltantes colores planos, contrastantes entre sí, efecto reforzado por su tratamiento sin perspectiva y la ausencia de transición entre unos y otros tonos ${ }^{2}$.

Así también en los esmaltes de las arquetas, la policromía de la escultura, y sería extensible a la orfebrería, la miniatura, la decoración textil (indumentaria, tapices) y a otras que no han llegado a nuestros días por la destrucción del soporte (Montero 1994; de referencia: Barral i Altet 2009). En el mismo sentido, como muestra de prestigio y de forma suntuaria, se policromaban los letreros de las grandes biblias románicas (véase, la de San Isidoro de León) en rojos, negros, marrones, azules y verdes. El color, unido al mayor módulo de los caracteres, conformaba un espectáculo visual no exento de la función práctica de esta escritura especial: marcar epígrafes o palabras relevantes (Suárez 1998: 851). Mostrar colorido era exhibir poder (Sánchez 1999), y así se refleja en la descripción de una casa en la cita de la anónima Historia troyana que abre estas páginas (Historia troyana 1976: 382), y 
que traduce el Roman de Troie de Benoît de Saint-Maure redactado un siglo antes, en pleno apogeo románico.

El interés de lo que hemos dado en llamar Románico repintado radica en su doble condición de testimonios continuadores evolucionados de unos modos histórico-artísticos casi perdidos, y de bienes culturales de valor etnográfico; un interés en tanto que documento o capa histórica del edificio a intervenir, del mismo modo que otros procesos constructivos, compositivos o decorativos de diferentes periodos. Como tal debiera considerarse y valorarse su tratamiento adecuado a cada caso concreto en el contexto de una intervención global en un templo románico, sin menoscabo de las decisiones proyectuales concretas que hacen de cada actuación un hecho singular como suma compleja de parámetros específicos asociados.

No proponemos en este artículo decir lo que se debe hacer con estos testimonios. No es una cuestión sencilla, y en la decisión última influirán factores de muy diverso tipo. Y ello, no por evitar posicionarnos en un tema, desde luego, siempre muy complejo y polémico cuando se trata de intervenir (restaurar) sobre el patrimonio cultural, sea éste inmueble, mueble o inmaterial. No lo hacemos porque estas páginas humildes tienen como único objetivo argumentar sobre la necesidad de identificar y documentar una práctica muy extendida y que ha llegado hasta el siglo XXI, claramente abocada a desaparecer sin dejar rastro, reconociéndola como un testimonio cultural. Son muchas las pérdidas en este campo en el último medio siglo, y mucho el trabajo de etnógrafos y antropólogos ahora para dar fe de manifestaciones materiales antes ubicuas y que hoy cuesta trabajo recomponer. Por otro lado, no nos es ajena la reflexión siguiente: la devoción de la gente del pueblo ha salvado muchas veces sin saberlo piezas que hoy forman parte del llamado Patrimonio Cultural, gracias a la reutilización y constante reinvención de las mismas (como las tallas de la Virgen, por ejemplo). Aparte de condicionamientos económicos, la misma devoción que provocó que en el XVIII se mutilaran horriblemente tantas imágenes románicas y protogóticas amoldándolas al gusto de las vestideras, las salvó de su destrucción, por la veneración a esa talla y no a otra. Esta misma reflexión se puede extender a los repintes "recientes" en la escultura monumental. En algún caso habrán salvado esos elementos de su sustitución. Finalmente, como la arqueología de la arquitectura enseña, la historicidad de un edificio se mide por sus estratos. Y la capa de pintura, por terrible que parezca, es uno de ellos. Por eso mismo, debe ser un parámetro que el restaurador ha de tener en cuenta, al margen de la decisión final que se tome, a la hora de documentar la práctica, valorarla, y no considerarla a priori uno de los primeros objetivos a eliminar.

Obviamente, las personas responsables de los toscos repintados que hemos repasado no lo han hecho homenajeando al citado autor de las Etimologías. Tampoco, por cierto, quienes desde otra posición frecuentemente dejaron libre de cal los interiores edilicios. Pero también sabemos que, al margen de cuál fuera la intención del artífice que proyectara la traza primera y la decoración de un edificio, por éste han pasado los siglos, y nuevos artífices han hecho y deshecho con mayor o menor fortuna. Hemos encontrado así estos testimonios y, ¿qué hacer? La discusión, si la hay, comienza en saber el punto en que se deben priorizar estos canecillos con cabezas humanas repintados de una manera tan naíf sobre la visión del canecillo mostrando la piedra vista; cuando hay que decidir si los capiteles del arco de gloria han de seguir ostentando esa paleta cromática excesiva o deben mostrar el color de la materia de que se componen, y ambas polémicas se doblan de la sensata seguridad de que cuando se colocaron por primera vez, seguramente estuvieron coloreados, y no precisamente de manera discreta. Por medio de un bucle histórico, se vuelven a reproducir estilemas que forman parte de una sintaxis plástica, de un lenguaje al que creemos que con mucha frecuencia no se reconoce como tal.

\section{Elementos románicos repintados: canecillos, capiteles y columnas}

En Soria se han conservado distintos ejemplos de esta costumbre de repintar escultura monumental románica, quizá por el aislamiento, quizá por la falta de medios para intervenir sobre los templos de pequeñísimas localidades rurales que por sí mismas no podían costear los reparos. La solución del repinte ocultaba el daño de una manera muy económica. En otras ocasiones, fue simplemente una 
cuestión de gustos, y el popular suele ser proclive a los contrastes cromáticos violentos y expresivos. Desde el Proyecto Cultural Soria Románica [www.soriaromanica.es] nos planteamos el estudio del Románico teniendo en cuenta que los edificios tienen una biografía que, si bien tradicionalmente ha sido despreciada, es indispensable para el estudio de este estilo. Como cualquier historiador o documentalista que investigue sobre edificios medievales sabe, muchas veces las noticias posteriores es el único medio que tenemos para saber lo que había antes, y de lo que no ha quedado constancia documental. También estos capiteles o canecillos humilde o grotescamente repintados nos dicen algo... si estamos receptivos.

Si ya de por sí es difícil poder datar los ejemplos de arte popular a partir de la documentación conservada, que no desciende a estas muestras que se entendían de tan poca importancia que no merecía la pena individualizar, qué decir de los repintes de la escultura monumental de la iglesia o de algunos elementos arquitectónicos. La documentación procedente de los Libros de Fábrica y similares que hemos consultado emplea una multiplicidad de verbos para expresar la pintura sobre madera: dorar, pintar, estofar, jaspear, encarnar... pero es mucho más parca cuando se trata de pintar sobre elementos murarios. El encalado posterior, o el deseo de sacar la piedra, ha ocultado o destruido estas muestras artísticas devaluadas, por la incorrección de sus formas o la presunta falta de calidad. No obstante, se debe señalar que representan la continuidad de una práctica secular tendente a colorear casi todo el espacio del templo, sin discriminar entre muros enlucidos o elementos propios de la escultura monumental.

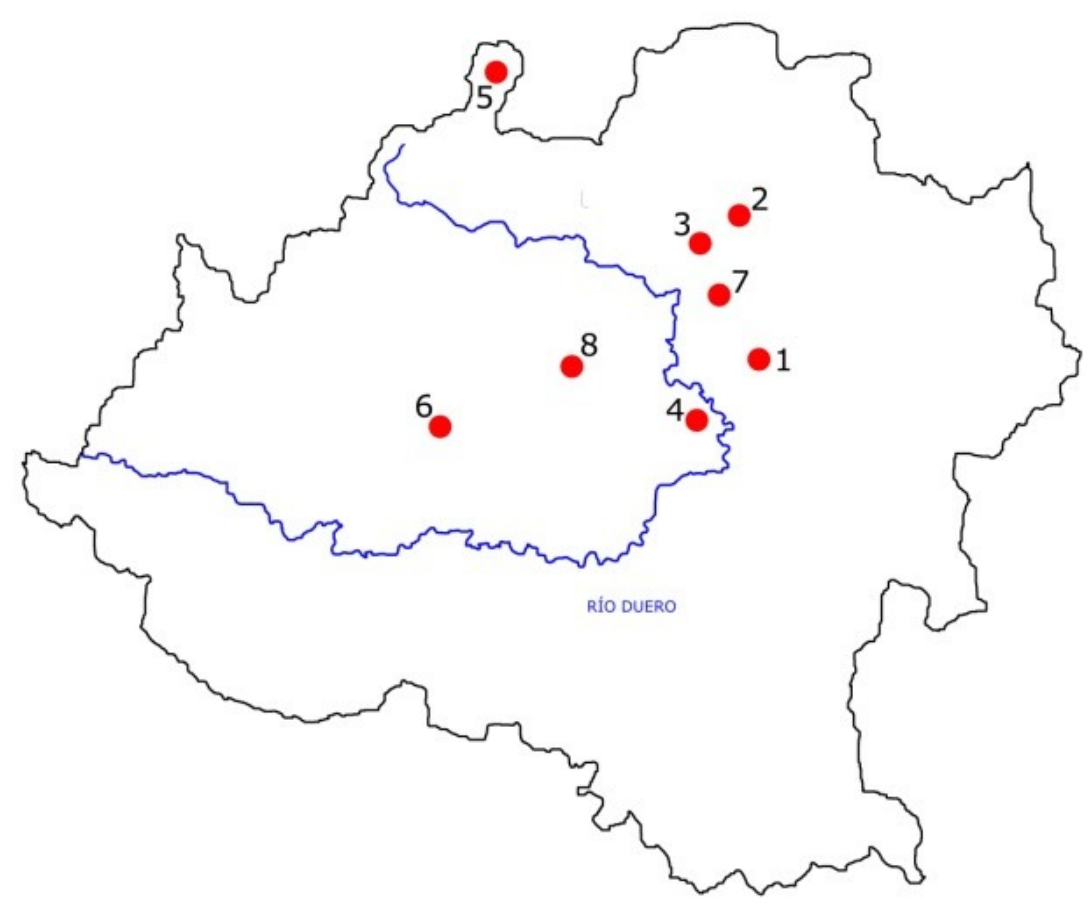

Mapa con la localización de los sitios citados

1. Carazuelo

2. Cuéllar de la Sierra

3. Fuentelsaz de Soria

4. Miranda de Duero

5. Montenegro de Cameros

6. Rioseco de Soria

7. Ventosilla de San Juan

8. Villabuena 
Si no románica, casi con seguridad se puede datar en la época medieval tanto los restos de policromía en los capiteles del arco de gloria como en las columnas del mismo de la ermita de San Mamés en Montenegro de Cameros [figura 1].
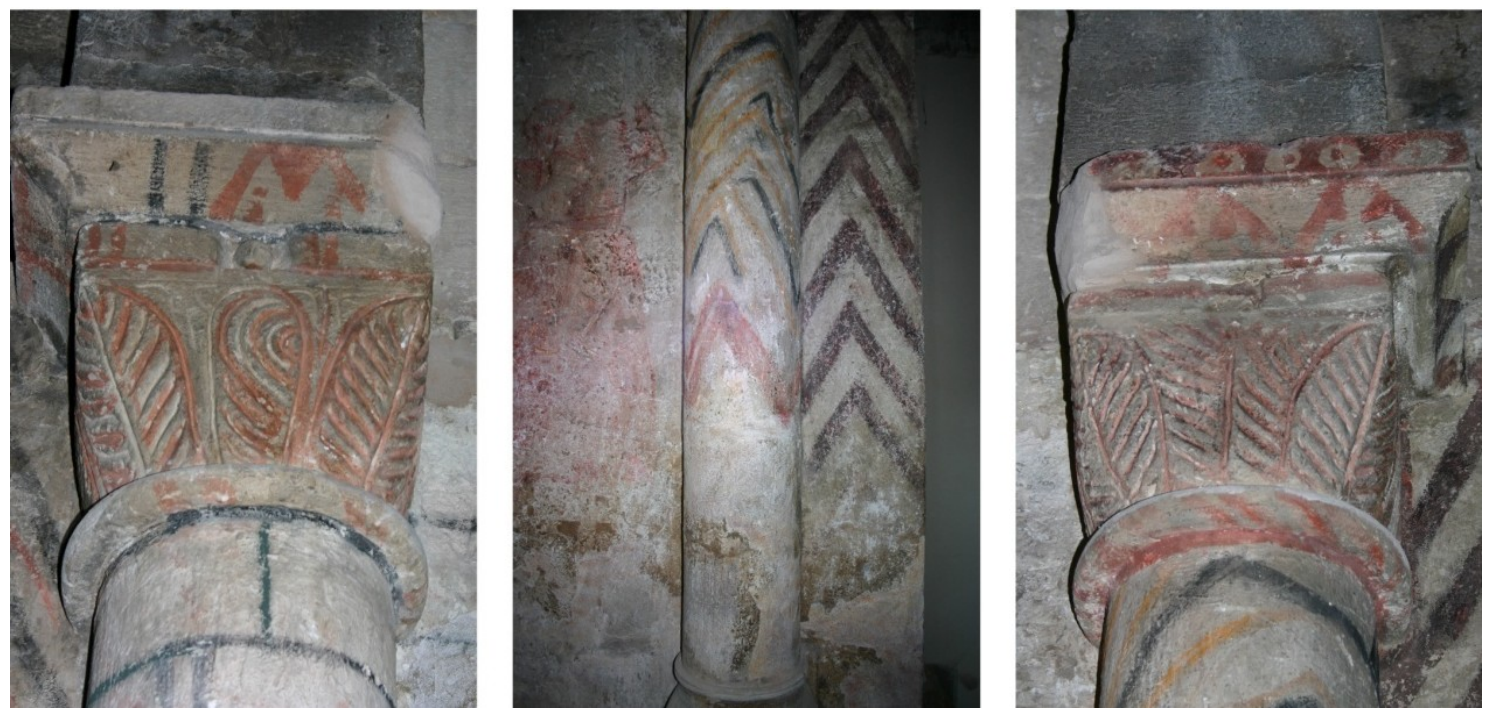

Figura 1. Capiteles y columna policromados del arco de gloria de la ermita de San Mamés, Montenegro de Cameros

Así pues, los testimonios conservados se erigen prácticamente en el único medio de que disponemos hoy de conocer estas sencillas "obras" realizadas por maestros locales ya en época postmedieval, moderna o contemporánea. Dejamos otros repintados (falsos despieces de sillería, falsos adovelados, llagueados...) para otra ocasión, y nos vamos a centrar en las páginas que siguen en columnas, capiteles y canecillos románicos repintados, correspondientes a las parroquias sorianas de Ventosilla de San Juan, Cuéllar de la Sierra, Fuentelsaz de Soria, Miranda de Duero, Carazuelo y la ermita de Rioseco de Soria, con el convencimiento de la absoluta falta de atención académica que hasta ahora se les ha dispensado, pues a esa factura popular de la que tradicionalmente ha huído y ha despreciado la Historia del Arte, se une su ausencia de vocación iconográfica ${ }^{5}$. Estos repintes, por tanto, no establecen programas, sino que colorean iconografía precedente.
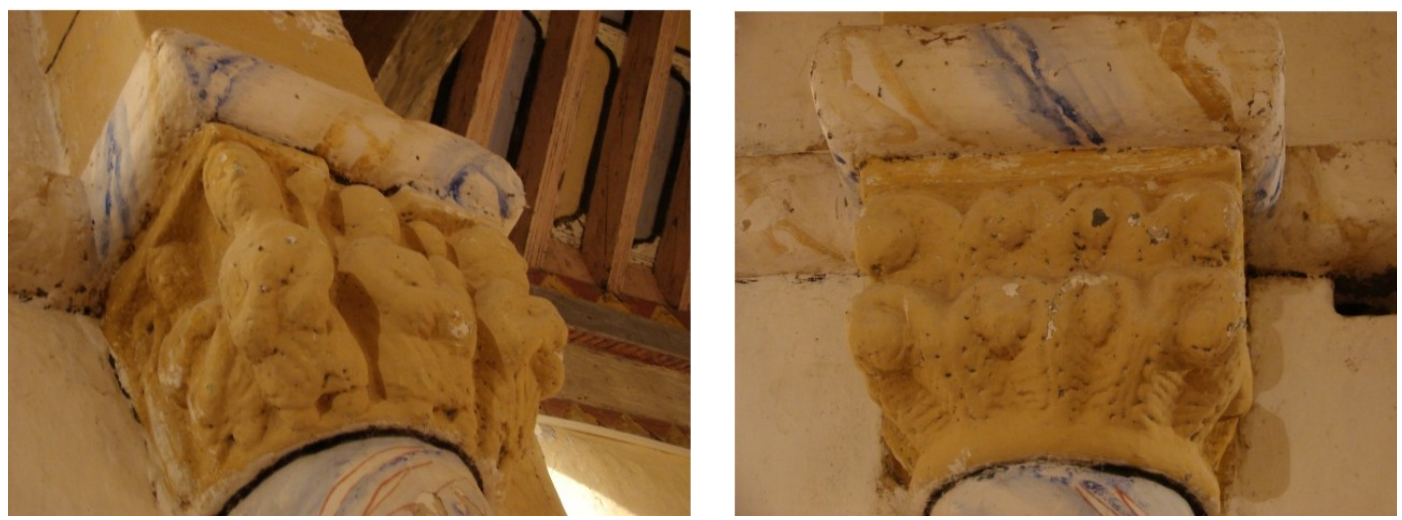

Figura 2. Capiteles repintados y cimacios del arco de gloria de la parroquia de San Agustín, Ventosilla de San Juan

La parroquia de San Agustín, en Ventosilla de San Juan, es una muestra de este gusto popular conseguido con medios humildes, lo que se advierte especialmente en su arco de gloria y en los capiteles que lo sostienen [figura 2]. Si la rosca del arco está decorada con pintura amarilla que imita 
el clásico despiece de dovelas marcado en negro, los propios capiteles están embadurnados de ese mismo color, alternando con cimacios, línea de imposta y fustes de las columnas, que se jaspearon.

Otro ejemplo, todavía más sencillo, lo ofrece la parroquia de Villabuena. Únicamente el volumen labrado en piedra del capitel de la imagen, acentuado por sus sombras, resalta dentro de la plana decoración con la que tan sólo se han querido realzar, en estilo monocromo, los elementos decorativos que caracterizan a esta sencilla arquitectura románica [figura 3]. El plinto y la basa de la pilastra de este arco de gloria rompen la monotonía de la composición con un tratamiento no menos sencillo y uniforme que el del resto del conjunto, pero con diferente elección dentro de la escasa paleta cromática con que a buen seguro contaba el artista. Este ejemplo, correspondiente a la cabecera de la iglesia de San Miguel Arcángel, responde en cuanto a su arquitectura a un tipo habitual en la provincia de Soria. De igual modo, su repinte no escapa a la norma repetida del Románico repintado soriano, que el presente estudio aborda.

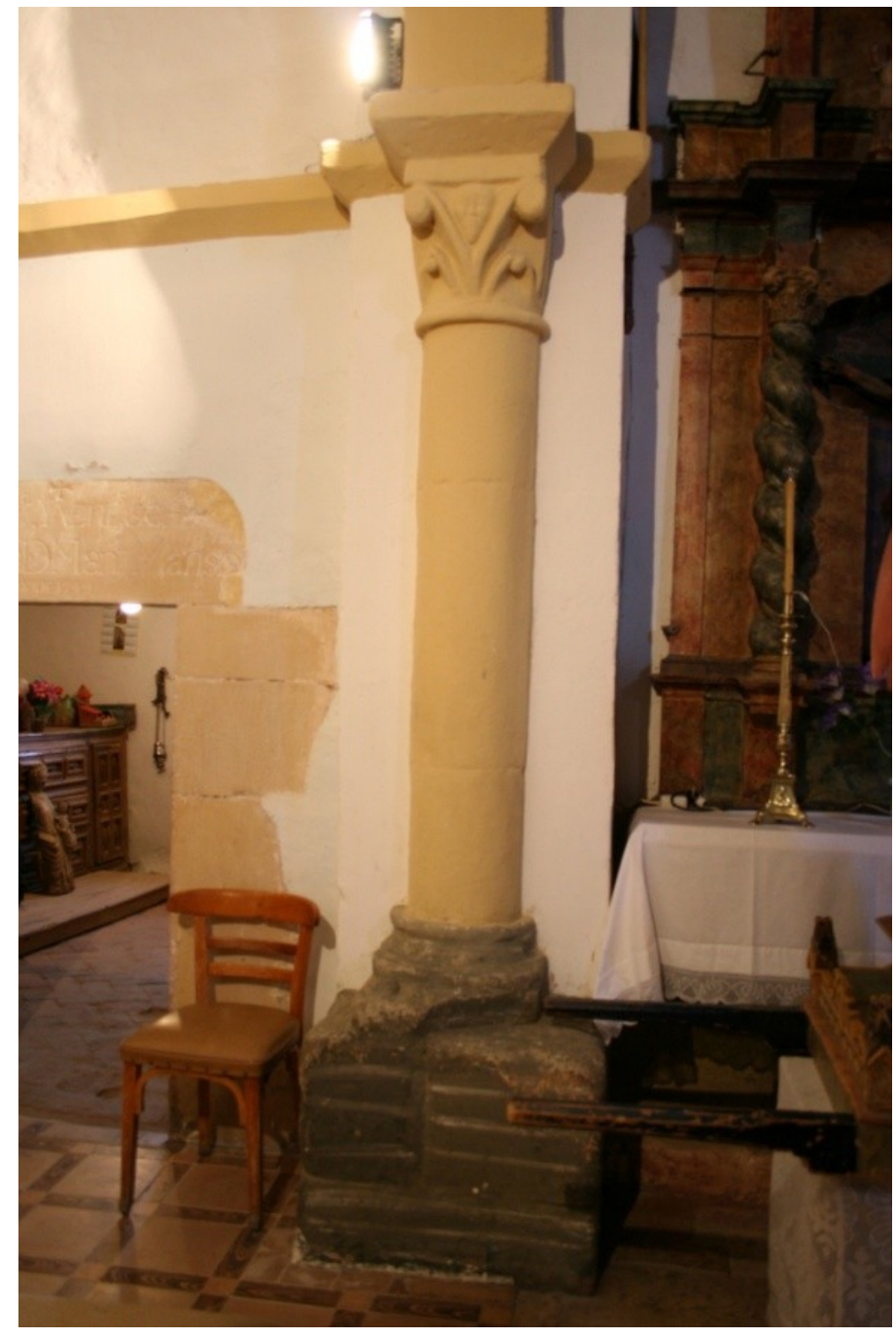

Figura 3. Columna y arranque del arco de gloria de la parroquia de San Miguel Arcángel, Villabuena

La parroquia de San Miguel de Cuéllar de la Sierra reúne una serie de muestras de gusto popular que la hacen singularmente interesante para un análisis como el que nos ocupa estas páginas. Si en el exterior se aprecian testimonios de buen trabajo advertibles en el solado de cantos rodados que decora el pórtico popular y parte del exterior del templo en su lado meridional, o las lajas de piedra que forman el tejado de su ábside, en el interior nos esperan curiosas sorpresas concentradas en la cabecera de la iglesia. A la pintura del presbiterio, antes mentada, se le une la parte más singular: los 
dos capiteles de su arco de gloria, ambos labrados en época románica con decoración geométrica y enormes cimacios también esculpidos [figuras 4 y 5 ].

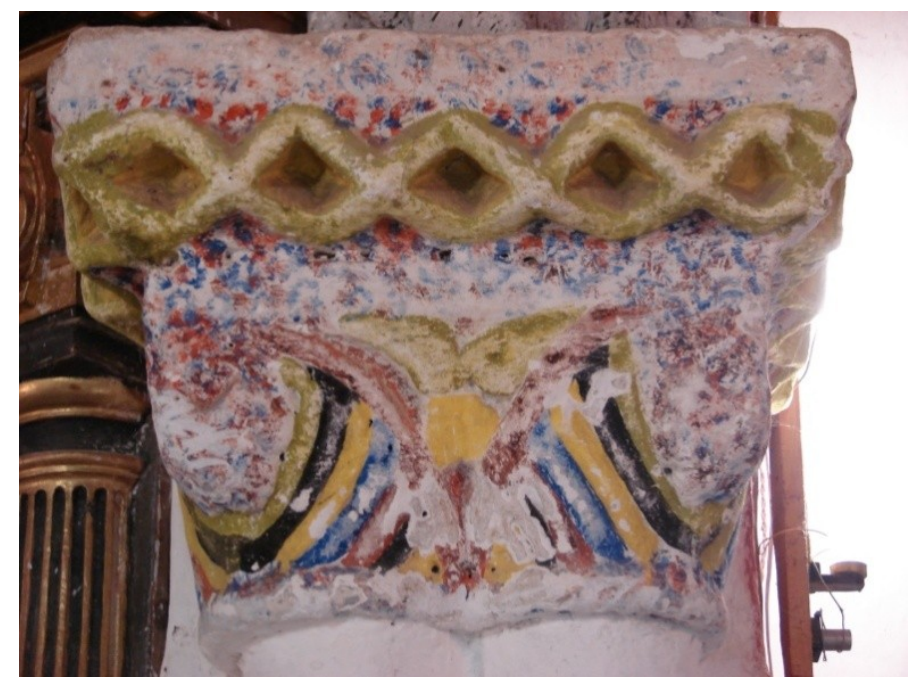

Figura 4. Capitel repintado del lado del Evangelio de la parroquia de San Miguel, Cuéllar de la Sierra

La labor medieval hoy se aprecia peor (o se resalta mejor) por el grosero y colorista repintado con pintura plástica que recubre por completo estas muestras de escultura monumental. Para completar el conjunto, tanto el arco de gloria como el que separa presbiterio de ábside han sido también repintados con simulación de despiece de dovelas. En el primer caso en gris; azul en el segundo. Bien se puede decir que una imagen vale todas las palabras que pudieran describir este caso.

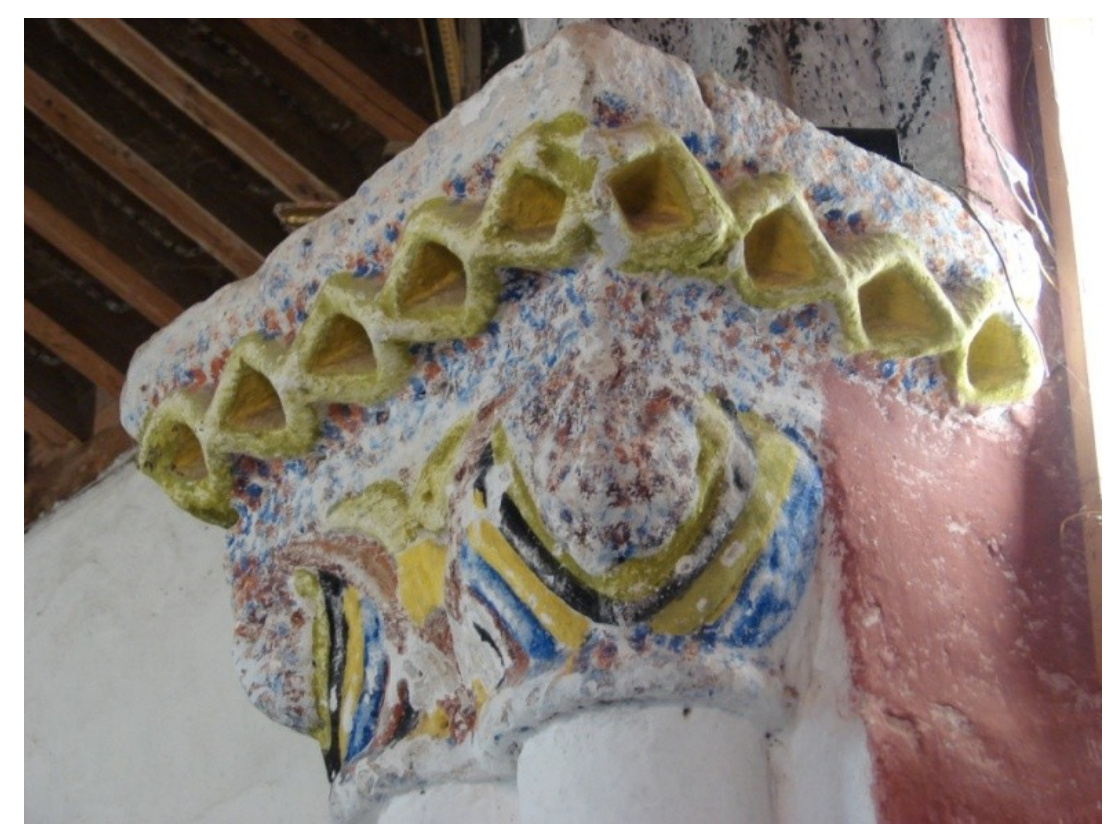

Figura 5. Capitel y cimacio repintados del lado de la Epístola de la parroquia de San Miguel, Cuéllar de la Sierra

La parroquia de Santo Domingo de Guzmán, en Fuentelsaz de Soria, es otra de las iglesias singularizadas por estas muestras de arte popular, en que merece la pena detenerse. Sin duda, la parte más singular la constituyen dos parejas de canecillos, en origen situados en el exterior del templo, y recolocados en el interior a comienzos de la Edad Moderna de forma simétrica para sostener la artesa que cubre la nave única [figuras 6 y 7]. 


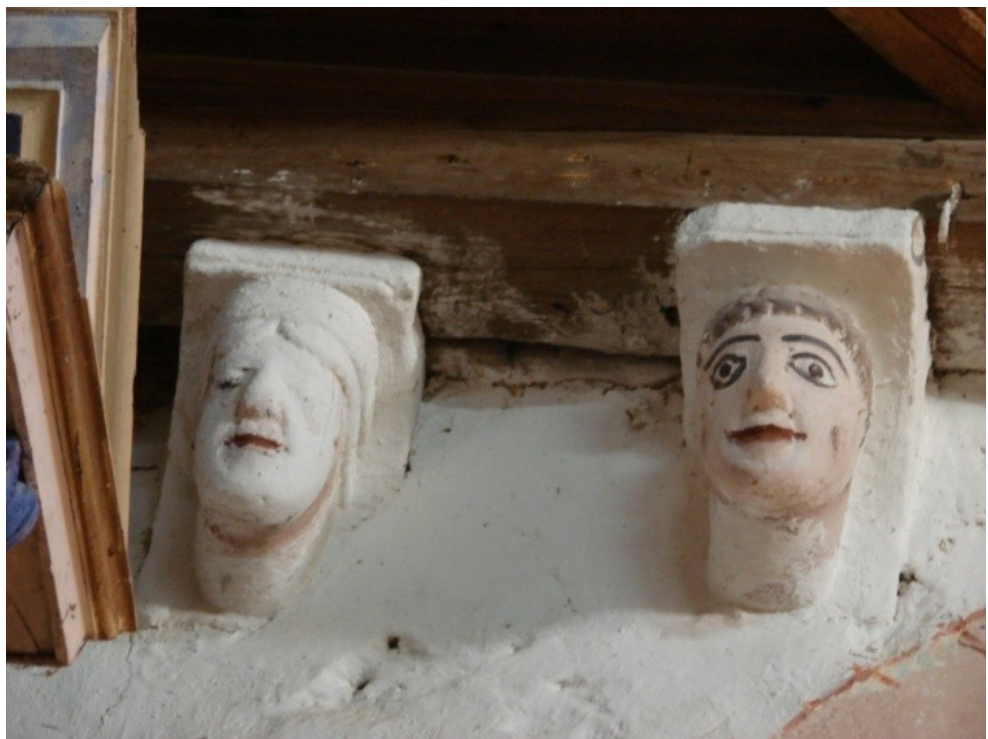

Figura 6. Canecillos repintados del lado de la Epístola en la parroquia de Santo Domingo de Guzmán, Fuentelsaz de Soria

Trátase de cuatro canes figurativos, que muestra cada uno una cabeza humana, un motivo muy extendido en el Románico. A alguien le debieron parecer muy simples y de difícil identificación, optando por colorear dichas cabezas perfilando distintos de sus elementos anatómicos (cabellos, ojos, labios, mentón) y algunos abalorios, invención de dicha mano.

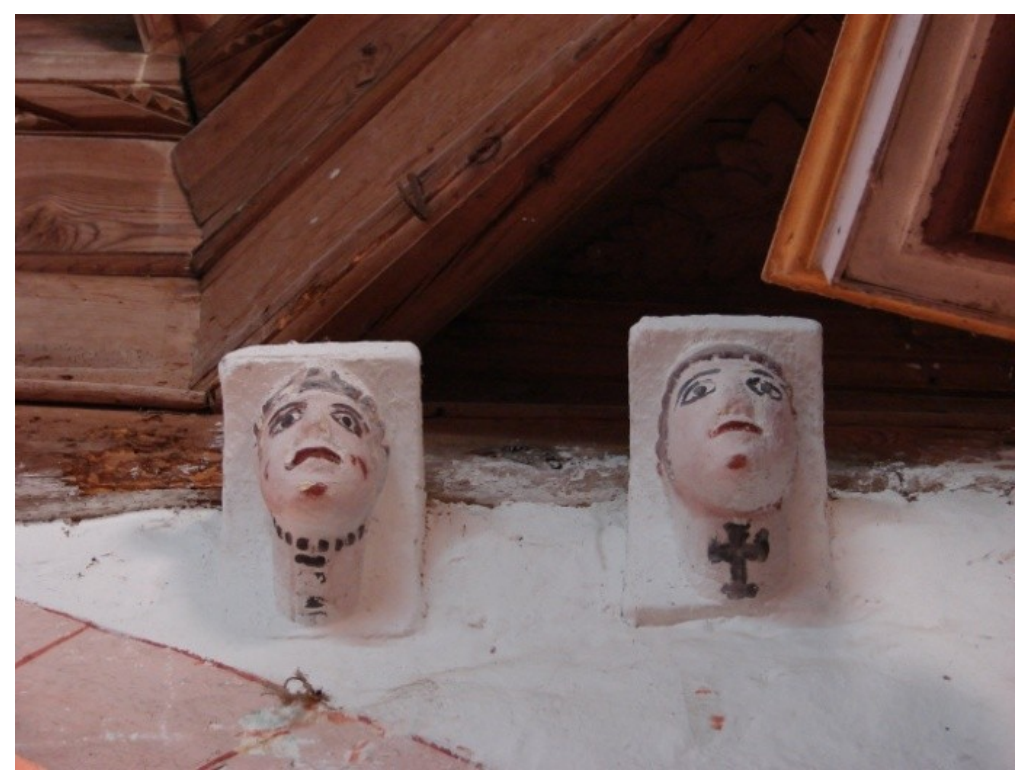

Figura 7. Canecillos repintados del lado del Evangelio en la parroquia de Santo Domingo de Guzmán, Fuentelsaz de Soria

La ermita de la Virgen del Barrio, en la localidad de Rioseco de Soria, se sitúa a escasos cien metros de la parroquia de la localidad. Ambas se ubican a las afueras del pueblo, sin construcción o masa arbórea que las separe, con lo que se consigue una curiosa duplicidad románica. El interior, y concretamente la cabecera de la ahora ermita, acoge una singular y diversa muestra del que llamamos Románico repintado. La superficie curvada y encalada que remata el ábside se ocultó parcialmente con un retablo en época barroca, completándose el conjunto decorativo en los laterales del elemento mueble con un cortinaje fingido, en colores y formas muy del gusto de la 
época. Para resaltar este efecto, debió de parecer necesario dotar de un cromatismo similar al arco de Gloria que antecede a esta cabecera. Este último tratamiento de un elemento arquitectónico y decorativo paradigmático del periodo románico, se aplicó en un momento impreciso que bien pudiera ser reciente, pues responde a un carácter menos claramente determinado que el anterior. Y

es el modo empleado en esta última decoración y el elemento sobre el que se aplica, lo que convierte a los capiteles del que forman parte, en uno de los ejemplos destacados del Románico repintado [figura 8].

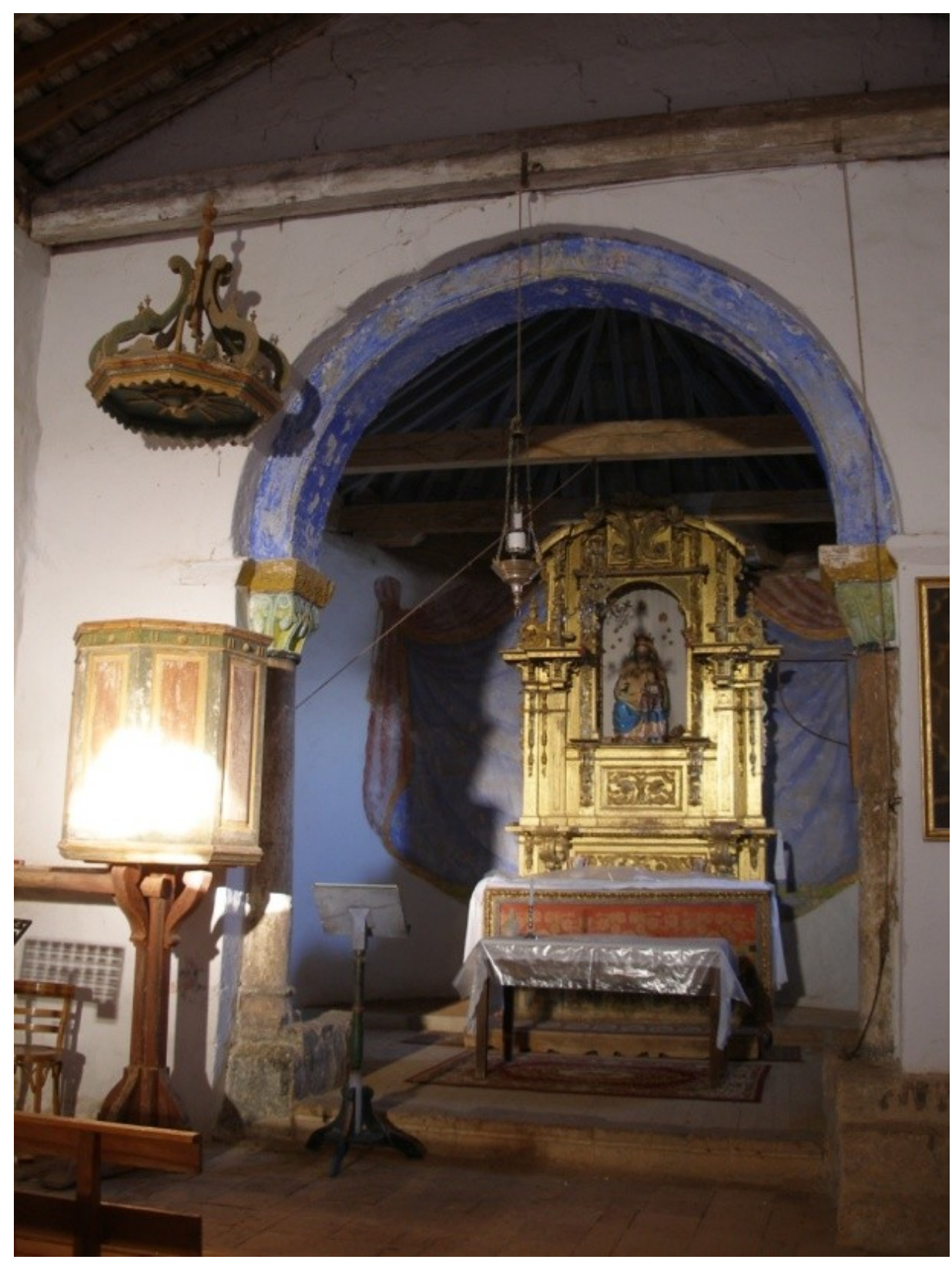

Figura 8. Arco de gloria repintado de la ermita de la Virgen del Barrio, Rioseco de Soria.

Como complemento añadido en época reciente a la decoración barroca de la cabecera de la ermita, los dos capiteles del arco reciben un tratamiento cromático no exento de criterio y de intencionalidad, a la hora de querer representar unos colores próximos a la decoración vegetal labrada en el capitel, diferenciados o en combinación según el caso, con los volúmenes decorativos o arquitectónicos que los enmarcan [figura 9]. 

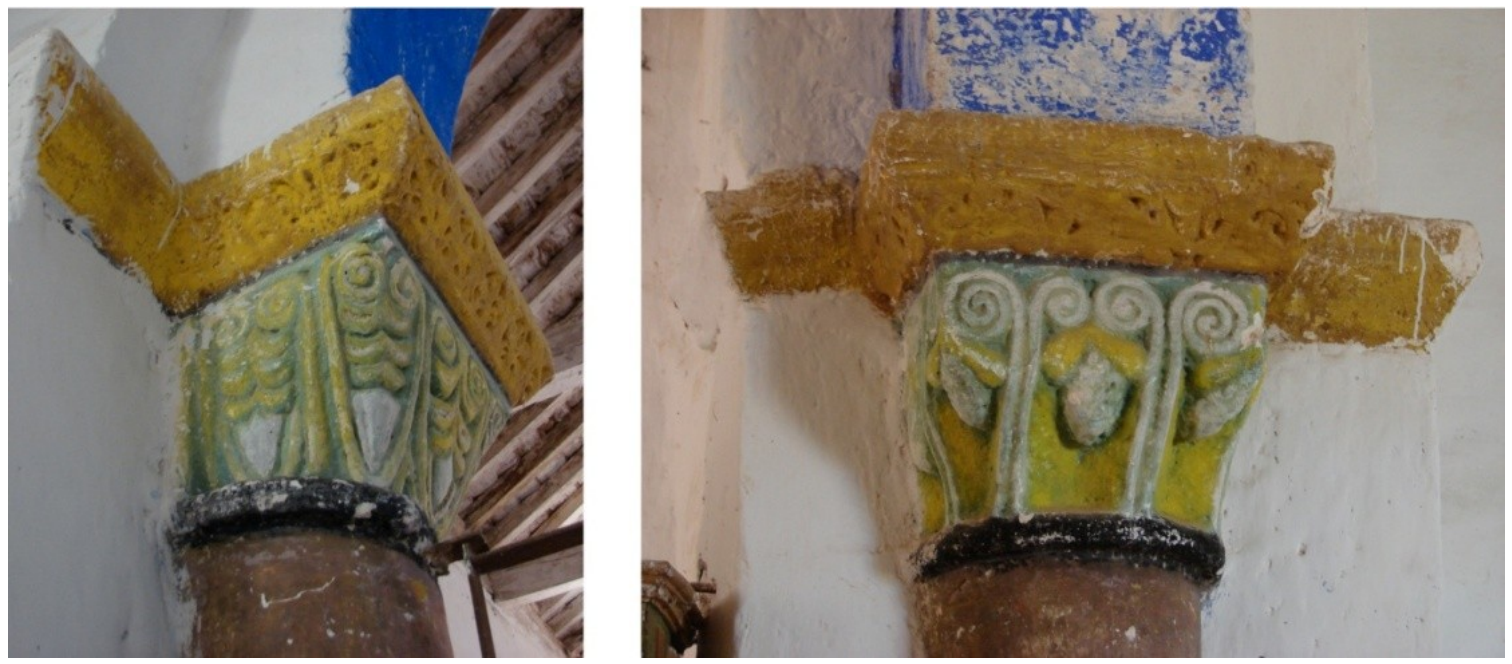

Figura 9. Capiteles y cimacios repintados del arco de gloria de la ermita de la Virgen del Barrio, Rioseco de Soria

\section{Epílogo, o confirmación de lo temido}

Terminado el artículo, advertimos en la bibliografía ${ }^{6}$ la presencia de otro elemento repintado, un capitel del arco de gloria de la iglesia de los Santos Justo y Pastor de Carazuelo, en su lado de la Epístola. La pintura perfila en colores azules y rojos los nervios de sus hojas y palmetas, marcando en gris las bolas en que rematan sus volutas, y su baquetón. Los trazos azules, además, marcan en zigzag algunas formas con sentido puramente ornamental, sin correspondencia con talla previa, a juego con el resto de azules. Enterados de que la iglesia había sido intervenida en 2003, acompañados del párroco nos presentamos en ella, no sin cierto temor. Nada más entrar, observamos cómo la "limpieza" había sido exhaustiva y no quedaba huella de lo que las fotografías anteriores a esa fecha mostraban. El capitel de piedra vista, a nuestro parecer con menos interés que la sencilla pero delicada policromía anterior, había sufrido la misma suerte que el falso cortinaje que enmarcaba el retablo del ábside: había desaparecido. El temor se confirmó [figura 10] ${ }^{(7)}$.
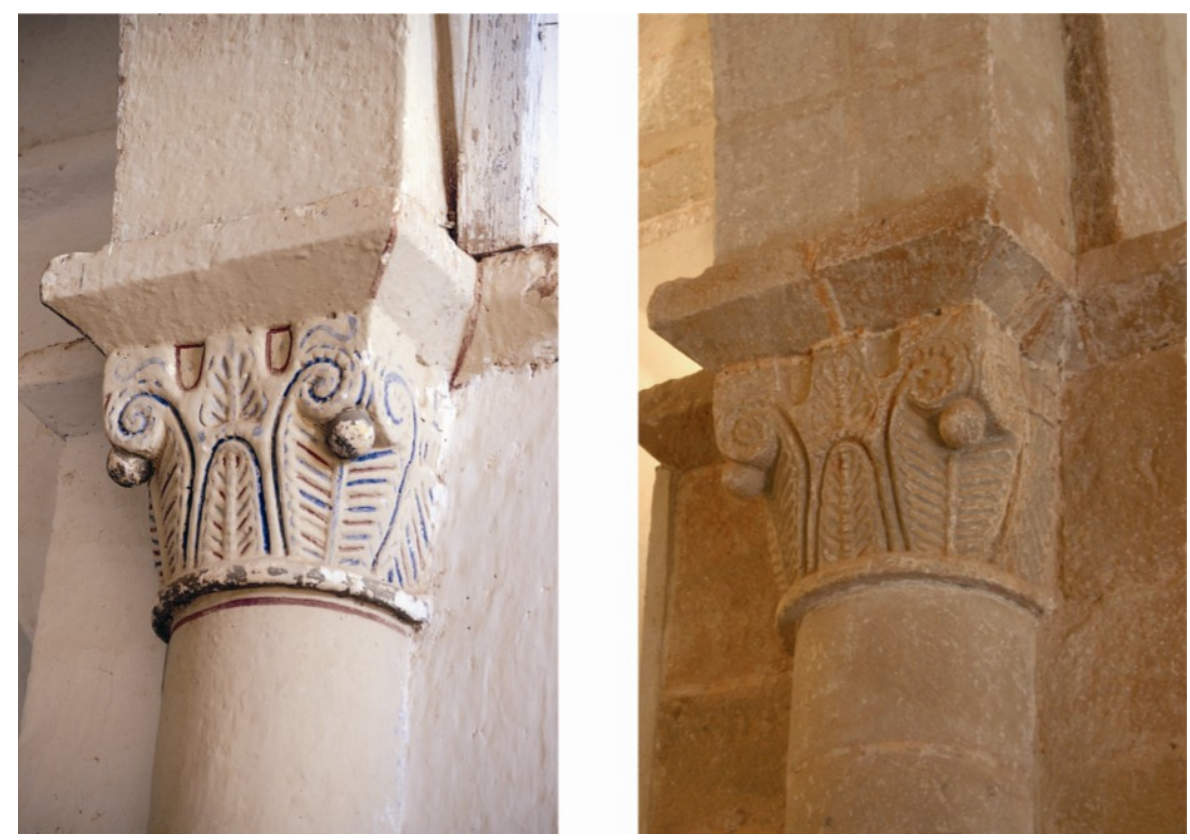

[Figura 10] Capitel del arco de gloria de la parroquia de los Santos Justo y Pastor, Carazuelo, antes y después de 2003. 
Poco se puede concluir de la lectura de las páginas precedentes. Si acaso, excitar alguna duda (otra más) de las que cotidianamente asaltan a quienes trabajan con patrimonio histórico-artístico y han de tomar decisiones. No obstante, estamos convencidos de que la reflexión en torno al canon artístico y su relación con el gusto popular es un campo poco tratado. Uno y otro ni siquiera compiten en el mismo nivel de significación ni de registro. Por ello este artículo, humilde como las manifestaciones que trata, tan sólo ha pretendido poner delante (ex-poner) de la mesa de trabajo unas policromías casi neorrománicas que, de puro llamativas, han sido invisibilizadas en la reflexión teórico-estética y en la práctica restauradora. Unas policromías, o repolicromías, que se están destruyendo con el mismo (poco) criterio que el de "sacar la piedra" por sacarla. Por creer que es mejor, o más bonito, sin entrar en otras consideraciones que son, a fin de cuentas, las que han motivado este artículo.

\section{Notas}

[*] El Proyecto Cultural Soria Románica es un plan de conservación, difusión y divulgación del Románico de la provincia de Soria que se desarrolla entre 2007 y 2010. La Junta de Castilla y León promueve y financia este proyecto, gestionado por la Fundación Duques de Soria, con la colaboración del Obispado de Osma-Soria, en virtud del convenio firmado por las tres instituciones. Más información en www.soriaromanica.es [Todas las fotografías que ilustran estas páginas son inéditas, y propiedad de Soria Románica].

[1] No vamos a tratar la cuestión de los revocos en estas páginas. Tan sólo, señalar la vigencia de la polémica en torno a ellos, y tres reflexiones muy recientes. Una mostrando, con el ejemplo de Santa María de Taüll (Lleida), que también se revocaban muros exteriores (VVAA. 2008). Otra, la conferencia que pronunció Jaime Nuño con el sugerente título de "Menosprecio del revoco y alabanza de la piedra. Las agresiones de una estética absurda", referenciada en la bibliografía. Finalmente, el recentísimo descubrimiento de un sinfín de grafitos románicos en la iglesia de San Miguel de San Esteban de Gormaz, por parte del Proyecto Cultural Soria Románica, al que pertenecemos.

[2] Al respecto de la influencia y el valor pedagógico de la ilustración de los manuscritos medievales, en la formalización y la sintaxis compositiva de la pintura mural románica, resultan de gran interés las aportaciones de Milagros Guardia (2006) y de $\mathrm{M}^{\mathrm{a}}$ de los Ángeles de las Heras (1984). En ambos estudios se establecen relaciones evidentes entre diversas corrientes y ejemplos concretos de representaciones figuradas en miniaturas medievales, y algunos de los testimonios conservados de pintura mural románica en la península ibérica y en Francia. Igualmente se contextualizan estas relaciones e influencias en el marco de las circunstancias históricas, económicas y geopolíticas que las hicieron posibles. Se plantean los procesos mediante los cuales representaciones de los códices se usaban como modelo y se trasvasaban, adaptándose a una arquitectura reciente pero preexistente, siguiendo o reinterpretando parámetros habituales de las miniaturas a la hora de incluir ciertas representaciones figuradas en relación con los elementos arquitectónicos que irrumpían en medio del programa iconográfico. Parece demostrarse cómo el embellecimiento con escenografía figurada e historiada del interior de algunos templos en el Románico, con posterioridad a la culminación de sus procesos constructivos, se trataba de una circunstancia aleatoria que respondía las posibilidades del momento a llevarlo a cabo. La concepción original del templo, como regla general y con más motivo en los enclaves alejados de los círculos de poder, plantearía la formalización de unos acabados interiores superficiales con un embellecimiento cromático ceñido al marcaje de los elementos arquitectónicos y decorativos ajenos a la planitud de los muros. Éstos enriquecerían sus irregulares enjalbegados con despieces de fingida sillería, quizás la primera manifestación de la búsqueda de un efecto, que como hemos descrito, tiene su máximo apogeo en el Barroco, y que sigue latente hasta la actualidad.

[3] Por ejemplo, el conservado en el Archivo Catedralicio de El Burgo de Osma, miniado por Martino el año 1086, último de los escritos con letra visigótica, pero con sintaxis plástica ya románica.

[4] En tiempos de los Padres de la Iglesia se planteó esta cuestión con el canto y, posteriormente, con la legitimidad o no de la música integrada dentro de la liturgia. Uno de los argumentos que se esgrimieron, con éxito, fue que la sonoridad de los himnos hacía más atractiva la estancia en el templo, como bien expresó Ambrosio, y se lo reconoció Agustín de Hipona: "Entonces fue cuando 
se estableció que cantasen los fieles himnos y salmos, según se acostumbraba ya en las iglesias de Oriente, para entretener y divertir el tedio y la tristeza que pudiera acabar de sobrecoger al pueblo" (Confesiones... lib. IX, cap. VII.15, 185), y el obispo milanés comenzó a componer himnos para dotar de repertorio. El propio Agustín enuncia bien la ambivalencia de la actitud de la Iglesia ante la música: "Así estoy vacilando entre el daño que del deleite de oír cantar puede seguirse y la utilidad que por la experiencia sé que puede sacarse; y más me inclino (sin dar en esto sentencia irrevocable ni definitiva) a aprobar la costumbre de cantar, introducida en la Iglesia, para que por medio del aquel gusto y placer que reciben los oídos, el ánimo más débil y flaco se excite y aficione a la piedad. Esto no quita que yo conozca y confiese que peco y que merezca castigo, cuando me sucede que el tono y canto me mueve más que las cosas que se cantan, y entonces más quisiera no oír cantar" (Confesiones... lib. X, cap. XXXIII.50, 229-230). Esta ambigüedad se ha manifestado también con respecto al ornato de los templos, como diversas reformas monásticas, con tendencia a la aniconía, manifestaron.

[5] Hasta donde sabemos, a lo sumo aparecen alguna vez nombrados en las descripciones formales de los templos, pero son aspectos que, a no ser que sean sumamente llamativos, suelen incluso ahí pasarse por alto.

[6] Nuño (2002: 346), reproducido también en Porras Gil (2008: 99).

[7] Agradecemos a Jaime Nuño su amabilidad a la hora de cedernos la fotografía del capitel repintado de Carazuelo, publicado previamente en la referencia expuesta en la nota anterior.

\section{Bibliografía}

AGUSTÍN DE HIPONA. Confesiones, traducidas según la edición latina de la congregación de San Mauro, por el R. P. Fr. Eugenio Ceballos. Biblioteca Virtual Miguel de Cervantes.

BARRAL I ALTET, Xavier (2009). "Debats sobre la pintura romànica". En L'art romànic català a debat. Barcelona: Edicions 62: 179-204.

GUARDIA, Milagros (2006). "Enluminure et peinture murale du Nord au Sud des Pyrénées: La syntaxe ornementale et ses thèmes". En Les Cabiers de Saint-Michel de Cuxa, XXXVII 'Vers et à travers l'art roman: la transmission des modèles artistiques. Actes des XXXVIIIéme Journées Romanes de Cuxa (6-13 juillet 2005)': 175-196.

DE LAS HERAS, $M^{a}$ de los Ángeles (1984). "Ermita de San Esteban de Viguera: Conexión de sus frescos con las diversas corrientes de la miniatura española”, Cuadernos de investigación: Historia, 10/2: 67-78.

Historia troyana en prosa y verso (1976). En Textos medievales españoles (Obras completas, 12). Ramón Menéndez Pidal, Madrid: Espasa-Calpe, 179-419.

Libro de los buenos proverbios que dijeron los filósofos y sabios antiguos (1971). Harlam Sturm (ed.), Lexington: Univesity Press of Kentucky. REAL ACADEMIA ESPAÑOLA: Banco de datos (CORDE) [en línea]. Corpus diacrónico del español. <http://www.rae.es> [Consultado el 1 junio 2009]

MONTERO CURIEL, María (1994). "La expresión del color en un bestiario medieval", Anuario de Estudios Filológicos, 17: 369-384.

NUÑO, Jaime (2002). “Carazuelo”. En Enciclopedia del Románico en Castilla y León. Soria, vol. I. M.Á. García Guinea y J.M. ${ }^{a}$ Pérez González (dirs.), Aguilar de Campoo, Fundación Santa María la Real-Centro de Estudios del Románico, 343-346.

NUÑO, Jaime (2008). "Menosprecio del revoco y alabanza de la piedra. Las agresiones de una estética absurda". En La pintura mural en el Románico, Taller organizado por las Agrupaciones de Desarrollo Local ADEMA y Tierras Sorianas del Cid en el contexto de las actividades del proyecto Europa Románica (Berlanga de Duero y El Burgo de Osma, 23 y 28 de octubre de 2008). 
PORRAS GIL, María Concepción (2008). "Lo que quedó detrás de las guerras: el arabismo en la arquitectura cristiana”. En Biblioteca. Estudio e investigación ['El Medievo en el Duero Oriental. Historia y Arte románico'], 23: 75-102.

SÁNCHEZ ORTIZ, Alicia (1999). "El color, símbolo de poder y orden social: apuntes para una historia de las apariencias en Europa", Espacio, Tiempo y Forma. Historia Moderna, 12: 321-354.

SUÁREZ GONZÁLEZ, Ana (1998). "Escribir para llamar la atención (Reflexiones sobre la escritura publicitaria en tres biblias del siglo XII". En Actas II Congreso Hispánico de Latín medieval (León, 11-14 de noviembre de 1997). Maurilio Pérez González (coord.), León: Universidad de León, vol. II, 849-864.

VVAA (2008). "Los acabados románicos: una aproximación a través de Santa María de Taüll”, Románico. Revista de Arte de Amigos del Románico, 6: 24-31.

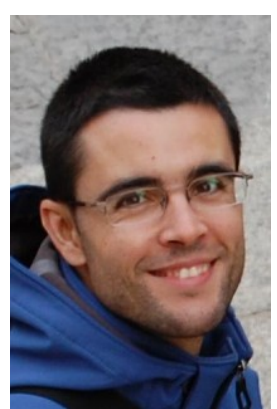

\section{J. Á. Esteras Martínez}

\section{jesteras@,soriaromanica.es}

José Ángel Esteras Martínez, Arquitecto del Proyecto Cultural Soria Románica. Máster en Restauración Arquitectónica por la Universidad Politécnica de Madrid. Coautor del Plan Director del Románico del Sur de Soria (2005-2006). Colabora investigando y publicando artículos con el Románico como tema principal.

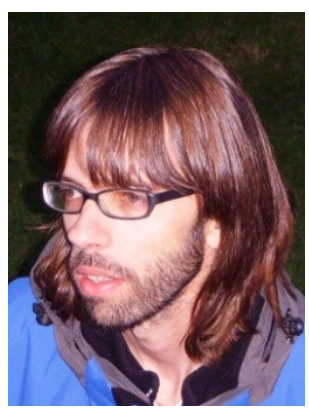

\section{J. Lorenzo Arribas}

\section{josemi@soriaromanica.es}

Josemi Lorenzo Arribas, Historiador del Proyecto Cultural Soria Románica. Doctor en Historia Medieval por la Universidad Complutense, es autor de cinco libros sobre distintos aspectos de la Edad Media, y más de sesenta artículos de diversos temas históricos, etnográficos y musicológicos 
